\title{
CARACTERÍSTICAS PRODUTIVAS DE DUAS CULTIVARES DE PIMENTÃo EM SUBSTRATOS ALTERNATIVOS
}

\author{
Tiago Luan Hachmann ${ }^{1}$, Graciela Maiara Dalastra², Marcia de Moraes Echer ${ }^{3}$, Claudia \\ Salim Lozano ${ }^{4}$, Roberto Rezende ${ }^{5}$
}

\footnotetext{
${ }^{1}$ Engenheiro Agrônomo, Doutorando no Programa de Pós-Graduação em Agronomia, Universidade Estadual de Maringá, Maringá (PR). Email: tiagohach@gmail.com

${ }^{2}$ Engenheira Agrônoma, Doutoranda no Programa de Pós-Graduação em Agronomia, Universidade Estadual do Oeste do Paraná, Marechal Cândido Rondon (PR).

${ }^{3}$ Professora Adjunta, Centro de Ciências Agrárias, Universidade Estadual do Oeste do Paraná, Marechal Cândido Rondon (PR).

${ }^{4}$ Engenheira Agrícola, Doutoranda no Programa de Pós-Graduação em Agronomia, Universidade Estadual de Maringá, Maringá (PR).

${ }^{5}$ Professor Associado, Departamento de Agronomia, Universidade Estadual de Maringá, Maringá (PR).
}

RESUMO: O aproveitamento de resíduos da agroindústria regional, ao mesmo tempo que diminui o custo de produção de cultivos hortícolas evita o descarte desses resíduos no meio ambiente. Neste trabalho se objetivou avaliar as características produtivas de três cultivares de pimentão utilizando substratos alternativos. $\mathrm{O}$ experimento foi conduzido em ambiente protegido, em delineamento de blocos ao acaso em esquema fatorial $3 \times 6$, com quatro repetições, sendo cada parcela composta por três vasos de $12 \mathrm{~L}$. O primeiro fator foi constituído de três cultivares de pimentão (Nice, Sofia e Romeo) e o segundo de seis substratos para o cultivo (S1 - substrato comercial, S2 - composto orgânico, S3 vermicomposto, S4 - composto orgânico e resíduo de aves na proporção 1:1 (V:V), S5 vermicomposto e resíduo de aves na proporção 1:1 (V:V), S6 - composto orgânico, vermicomposto e resíduo de aves na proporção 1:1:1 (V:V:V). O resíduo de aves pode ser aplicado na formulação de substratos para cultivo de hortaliças. As cultivares Sofia e Nice são as mais adequadas.

Palavras-chave: Capsicum аппиит L. Composto orgânico. Resíduo de aves. Vermicomposto.

\section{PRODUCTIVE CHARACTERISTICS OF SWEET PEPPERS IN ALTERNATIVE SUBSTRATES}

\begin{abstract}
The waste recovery of regional agroindustry, at the same time decrease the cost of production of horticultural crops avoids the disposal of such waste in the environment. This work aimed to evaluate the productive characteristics of three pepper cultivars using alternative substrates. The experiment was conducted in greenhouse in a randomized block design in a factorial $3 \times 6$ scheme, with four replications. The first factor consisted of three pepper cultivars (Nice, Sofia and Romeo) and the second of six substrates for cultivation (commercial substrate, organic compost, vermicompost, compost and poultry waste in the ratio 1:1 (V: V), vermicompost and poultry waste in the ratio $1: 1(\mathrm{~V}: \mathrm{V})$, and
\end{abstract}


finally a substrate composed of organic compost, vermicompost and poultry waste in the ratio 1: 1: $1(\mathrm{~V}: \mathrm{V}: \mathrm{V}))$. The residue can be applied to a substrate for growing vegetables. The Sofia and Nice cultivars are best suited.

Key words: Capsicum annuum L. Organic compost. Poultry waste. Vermicompost.

\section{INTRODUÇÃO}

O pimentão (Capsicum annuum L.), pertencente à família Solanaceae, é originário da América do Sul, entre a Bolívia e o Peru (SANJUÁn; GAVILAN, 2004). Seu cultivo é universal, estando presente praticamente em todos continentes. Esta hortaliça possui uma grande heterogeneidade de tamanhos, formas e cores, de forma que identificar cultivares adaptadas e que atendam aos princípios da produtividade, qualidade e rentabilidade, é o primeiro passo para se ter êxito nos cultivos (MACHADO et al., 2002).

O cultivo em ambiente protegido, tanto no sistema convencional quanto no sistema orgânico, tem sido uma tecnologia utilizada de forma competitiva e sustentável (DAREZZO et al., 2004). Uma das técnicas utilizadas no cultivo em ambiente protegido é o cultivo sem solo, uma prática desenvolvida para evitar que as doenças presentes no solo infectem a planta (VIDA et al., 2004). As principais vantagens desse sistema em relação ao convencional são o manejo mais adequado da água, o fornecimento adequado de nutrientes com redução do risco de salinização além da diminuição dos problemas sanitários (ANDRIOLO et al., 1999).

Um fator importante no cultivo sem solo é a seleção de um substrato ideal, o qual deve ter determinadas características como elevada capacidade de retenção de água, distribuição das partículas de tal modo que, ao mesmo tempo em que retenham água, mantenham a aeração das raízes, decomposição lenta, disponível no comércio e que seja de baixo custo (MELO et al., 2006).

A utilização de substratos produzidos a partir de resíduos oriundos de outros sistemas de produção agrícola da região de cultivo é uma excelente alternativa, visto que concilia preservação ambiental, agregação de valor ao produto e economia para o produtor. Dentro disso, o aproveitamento de resíduos de avicultura, se torna interessante, visto que é um material de alta disponibilidade e baixo custo. Esse resíduo é rico em matéria orgânica e nutrientes, podendo suprir a exigência nutricional das plantas (HACHMANN et al., 2013).

Diante disso, o objetivo do trabalho foi avaliar substratos formulados e seu efeito nas características produtivas de três cultivares de pimentão, em cultivo protegido.

\section{MATERIAL E MÉTODOS}

O experimento foi conduzido em casa de vegetação, sob estrutura de ferro galvanizado com teto em forma de arco, de dimensões 7 x $30 \mathrm{~m}$ e 3,5 m de pé direito. O teto 
foi coberto com filme plástico de polietileno de baixa densidade (PEBD) com filtro difusor e anti-UV de $150 \mu$ de espessura e as laterais fechadas com tela branca com $40 \%$ de sombreamento.

O experimento foi conduzido em delineamento de blocos ao acaso, em esquema fatorial 3 x 6, com quatro repetições, sendo o primeiro fator constituído de três cultivares de pimentão (Nice, Sofia e Romeo) e o segundo de seis substratos de cultivo (S1 - substrato comercial, S2 - composto orgânico, S3 - vermicomposto, S4 - composto orgânico e resíduo de aves na proporção 1:1 (V:V), S5 - vermicomposto e resíduo de aves na proporção $1: 1$ $(\mathrm{V}: \mathrm{V})$, S6 - composto orgânico, vermicomposto e resíduo de aves na proporção 1:1:1 $(\mathrm{V}: \mathrm{V}: \mathrm{V}))$. Cada parcela foi composta por três vasos, sendo as avaliações realizadas em todas as plantas. Os frutos das cultivares Nice e Sofia são do tipo quadrado, ou "block", com paredes grossas e de coloração vermelha e alaranjada, respectivamente, quando maduros. A cultivar Romeo possui frutos com formato semi-retangular e coloração verde limão quando imaturo.

O composto orgânico foi produzido utilizando restos vegetais de hortaliças, palha de tifton e esterco bovino, os quais ficaram em montes que foram revolvidos semanalmente, até a estabilização da mistura. $\mathrm{O}$ vermicomposto (húmus de minhoca) foi produzido a partir de esterco bovino, através da ação de minhocas. O resíduo de aves foi proveniente de aves poedeiras, sem presença de outros materiais (penas, cascas de ovos, restos de ração, etc.).

As misturas dos substratos foram realizadas com duas semanas de antecedência, para permitir a estabilização das mesmas. Após misturadas, foram umedecidas e deixadas em montes, cobertos com lonas transparentes e posteriormente colocadas em vasos com $12 \mathrm{~L}$ de capacidade.

As mudas de pimentão foram produzidas em bandejas de poliestireno expandido de 128 células, contendo substrato comercial. Foi transplantada uma muda por vaso quando estas apresentavam de quatro a cinco folhas definitivas. Os vasos foram dispostos em fileiras simples, no espaçamento de 1,20 x 0,40 m.

Por ocasião do transplante foram coletadas amostras dos substratos para análise física e química das misturas. A avaliação física do substrato foi realizada conforme metodologia descrita por Fermino (2003) para análise de substratos hortícolas, sendo avaliada a densidade de volume, densidade de partículas e porosidade. A análise química do substrato foi feita conforme metodologia descrita por Silva (2009).

A adubação foi realizada baseada na extração de nutrientes (fósforo e potássio) conforme Sanjuán e Gavilán (2004) via gotejamento, utilizando biofertilizante "supermagro", e complementada via pulverização foliar conforme a necessidade. O biofertilizante apresentava as seguintes características: $\mathrm{pH} 4,19 ; 1,75 \mathrm{~g} \mathrm{~L}^{-1}$ de N; 0,22 $\mathrm{g} \mathrm{L}^{-1}$

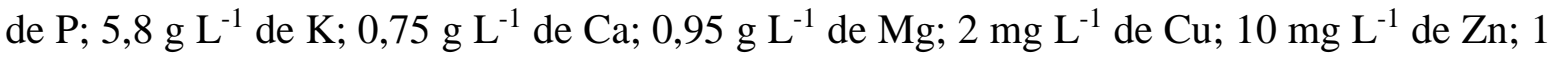
$\mathrm{mg} \mathrm{L}^{-1}$ de Mn e $71 \mathrm{mg} \mathrm{L}^{-1}$ de Fe. A irrigação foi realizada via gotejamento, utilizando fita flexível com vazão de $1,6 \mathrm{~L} \mathrm{~h}^{-1}$, aplicada diariamente, conforme a necessidade indicada pela 
evapotranspiração. Para tanto foram instalados mini tanques evaporimétricos, conforme metodologia proposta por Jadoski et al. (2006).

Foi instalado, no interior do ambiente de cultivo, um datalogger da marca Homis, modelo 494, programado para registrar os dados de temperatura e umidade relativa do ar a cada hora cheia do dia. Os dados de temperatura e umidade estão apresentados na Figura 1.

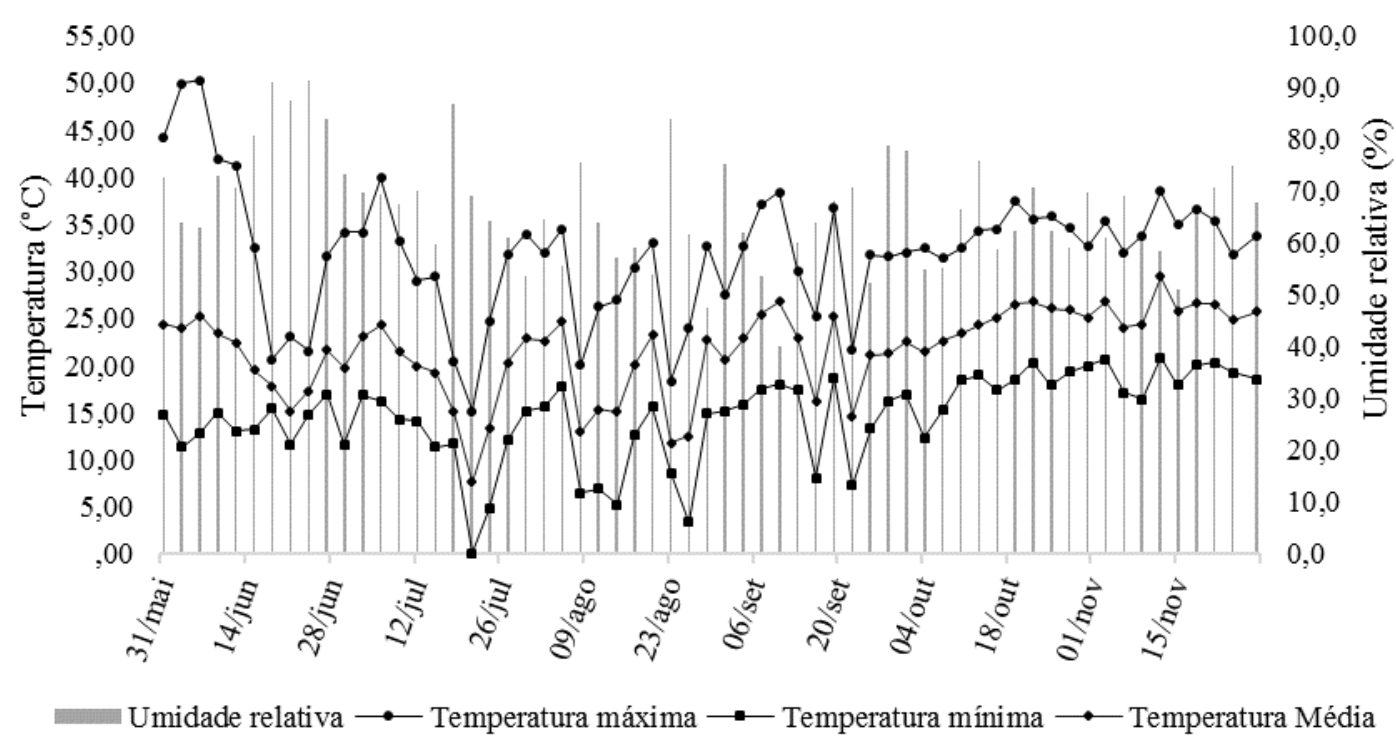

Figura 1. Temperatura mínima, máxima e média e umidade relativa média no ambiente de cultivo durante o período de condução do experimento.

As plantas foram conduzidas utilizando tutores e fitilhos. $\mathrm{Na}$ extremidade de cada fileira e a cada $1,20 \mathrm{~m}$ se colocou um tutor, que foi amarrado em fio de arame na parte inferior e superior. Quando as plantas começaram a florescer, foi passado um fitilho em zigzag duplo (no sentido de ida e volta entre as plantas). A primeira fileira de fitilhos horizontais foi colocada a uma altura de $15-20 \mathrm{~cm}$ acima da bifurcação do ramo, nos dois lados da planta. À medida que a plantas cresceram, foram colocadas outras linhas de fitilhos, distanciadas $25 \mathrm{~cm}$ das anteriores.

A colheita foi iniciada aos 74 dias após o transplantio (DAT) e se estendeu até os 179 DAT. Os frutos foram colhidos quando apresentavam mais de $70 \%$ da coloração definida para cada cultivar Nice e Sofia, e quando se apresentavam firmes para a cultivar Romeo. Os frutos colhidos foram conduzidos ao laboratório, onde foi realizada a classificação em "normais", "com defeito leve" e "com defeito grave", seguindo normas do Programa Paulista para a melhoria dos padrões comerciais e embalagens de hortifrutigranjeiros (CEAGESP, 1998). Posteriormente foi avaliado o número de frutos e a massa de frutos em cada uma das classes. Em seguida, os frutos normais foram avaliados quanto à massa média do fruto, comprimento, diâmetro transversal, índice de formato do fruto (relação comprimento e diâmetro) e espessura da polpa, medida na porção média dos frutos. Posteriormente foi estimada a produtividade $\mathrm{em}_{\mathrm{kg} \mathrm{m}}{ }^{-2}$.

Cultura Agronômica, Ilha Solteira, v.26, n.4, p.502-513, 2017 
Os dados foram submetidos à análise de variância e as médias comparadas pelo teste de Tukey utilizando o programa estatístico Sisvar (FERREIRA, 2011).

\section{RESULTADOS E DISCUSSÃO}

Na Tabela 1 são apresentados os teores de nutrientes e condutividade elétrica (CE) dos substratos utilizados no experimento. Os substratos onde foi acrescido resíduo de aves na mistura apresentaram maior condutividade elétrica, devido, principalmente, ao maior teor de potássio e outros nutrientes.

Tabela 1. Características química e físicas dos substratos utilizados.

\begin{tabular}{lcccccc}
\hline Características químicas & $\mathrm{S} 1$ & $\mathrm{~S} 2$ & $\mathrm{~S} 3$ & $\mathrm{~S} 4$ & $\mathrm{~S} 5$ & $\mathrm{~S} 6$ \\
\hline Condutividade elétrica $(\mathrm{dS} \mathrm{m}$ & -1 \\
$\mathrm{~N}\left(\mathrm{~g} \mathrm{~kg}^{-1}\right)$ & 0,75 & 1,63 & 2,04 & 3,92 & 4,50 & 2,70 \\
$\mathrm{P}\left(\mathrm{g} \mathrm{kg}^{-1}\right)$ & 5,00 & 5,27 & 5,78 & 1,38 & 1,08 & 8,21 \\
$\mathrm{~K}\left(\mathrm{~g} \mathrm{~kg}^{-1}\right)$ & 10,18 & 8,87 & 13,42 & 19,70 & 16,87 & 21,37 \\
$\mathrm{Ca}\left(\mathrm{g} \mathrm{kg}^{-1}\right)$ & 4,66 & 3,03 & 3,45 & 6,90 & 7,79 & 7,67 \\
$\mathrm{Mg}\left(\mathrm{mg} \mathrm{kg}^{-1}\right)$ & 49,18 & 30,78 & 20,90 & 40,04 & 37,40 & 49,39 \\
$\mathrm{Fe}\left(\mathrm{mg} \mathrm{kg}^{-1}\right)$ & 15,27 & 7,69 & 5,45 & 9,34 & 9,45 & 11,03 \\
$\mathrm{Mn}\left(\mathrm{mg} \mathrm{kg}^{-1}\right)$ & 3,68 & 3,77 & 3,03 & 3,06 & 3,29 & 3,57 \\
$\mathrm{Zn}\left(\mathrm{mg} \mathrm{kg}^{-1}\right)$ & 207,46 & 329,43 & 534,35 & 447,04 & 399,30 & 567,47 \\
$\mathrm{Cu}\left(\mathrm{mg} \mathrm{kg}^{-1}\right)$ & 51,28 & 149,54 & 119,96 & 150,81 & 190,88 & 224,88 \\
Características físicas & 55,94 & 114,87 & 72,70 & 114,90 & 77,91 & 126,10 \\
\hline Densidade de partícula $\left(\mathrm{g} \mathrm{cm}^{-3}\right)$ & 1,49 & 2,26 & 2,10 & 2,23 & 1,98 & 2,09 \\
Densidade úmida $\left(\mathrm{kg} \mathrm{m}^{-3}\right)$ & 512,1 & 946,6 & 786,5 & 836,3 & 826,2 & 908,3 \\
Densidade seca $\left(\mathrm{kg} \mathrm{m}^{-3}\right)$ & 226,7 & 590,7 & 250,7 & 486,1 & 422,2 & 467,2 \\
Porosidade total $\left(\mathrm{m}^{3} \mathrm{~m}^{-3}\right)$ & 0,41 & 0,46 & 0,62 & 0,36 & 0,47 & 0,49 \\
Macroporos $\left(\mathrm{m}^{3} \mathrm{~m}^{-3}\right)$ & 0,10 & 0,17 & 0,14 & 0,05 & 0,05 & 0,07 \\
Microporos $\left(\mathrm{m}^{3} \mathrm{~m}^{-3}\right)$ & 0,31 & 0,30 & 0,48 & 0,31 & 0,42 & 0,42 \\
\hline
\end{tabular}

S1 - substrato comercial; S2 - composto orgânico; S3 - vermicomposto; S4 - composto orgânico e resíduo de aves na proporção 1:1 (V:V); S5 - vermicomposto e resíduo de aves na proporção 1:1 (V:V); S6 - composto orgânico, vermicomposto e resíduo de aves na proporção 1:1:1 (V:V:V).

A condutividade elétrica variou de 0,75 a 4,50 para os substratos utilizados. De acordo com Andriolo et al. (2003) níveis de salinidade no ambiente radicular superiores a 4,0 dS m ${ }^{1}$ podem provocar redução do crescimento das plantas, queda no rendimento de frutos e distúrbios fisiológicos como a podridão apical dos frutos. Ayers e Westcot (1999) afirmam que uma condutividade elétrica de até $3,0 \mathrm{dS} \mathrm{m}^{-1}$ permitem um bom desenvolvimento para a maioria das culturas, porém a cultura do pimentão tolera uma salinidade próxima a 2,1 dS $\mathrm{m}^{-1}$, sendo classificada como moderadamente sensível à salinidade.

No experimento não foram observadas injúrias às plantas ou redução em produtividade decorrentes da salinidade excessiva no substrato. Segundo Ayres e Westcot (1999) para a cultura do pimentão, salinidades de 1,5;2,2; 3,3; 5,1 e 8,1 dS m mpovocam $^{-1}$ Cultura Agronômica, Ilha Solteira, v.26, n.4, p.502-513, 2017 
redução de produtividade de $0 \%, 10 \%, 25 \%, 50 \%$ e $100 \%$, respectivamente. Além disso, o biofertilizante apresentou baixa salinidade, o que pode ter contribuído para a estabilização da salinidade nos substratos.

Não foi observada interação entre substratos e cultivares para as características produtivas, sendo os fatores estudados isoladamente. Foi verificada diferença entre os substratos para número de frutos com defeito leve, massa de frutos normais, massa de frutos com defeito leve, massa média dos frutos, diâmetro transversal do fruto, comprimento do fruto, índice de formato do fruto e produtividade. Foi observado efeito das cultivares para as variáveis massa média dos frutos, diâmetro transversal do fruto, comprimento do fruto, espessura da polpa e índice de formato do fruto (Tabela 2).

No cultivo em vermicomposto (S3) foi obtido o maior número de frutos com defeito leve. Porém, mesmo com um número de frutos com defeito leve maior, não houve redução do número de frutos normais. O número total de frutos foi $36,63 \%$ maior do que no cultivo em substrato comercial (Tabela 2).

Mesmo sem ocorrer diferença estatística, o número de frutos com defeito grave e a massa de frutos com defeito grave foram maiores nos substratos onde foi utilizado resíduo de aves em maior proporção na composição (S4 e S5). O único defeito grave observado no experimento foi a presença de frutos com podridão apical, causada por deficiência localizada de cálcio. O cálcio, depois do $\mathrm{N}$ e K, é o nutriente mais exigido pelas plantas de pimentão. Esse nutriente está relacionado à elongação e divisão celular, além disso, possui função estrutural na parede celular, através dos pectatos de cálcio (FACTOR et al., 2008). Em condições de alta umidade relativa, baixas ou altas temperaturas (baixa taxa de transpiração), baixo teor de água no solo e salinidade, é possível ocorrer sintomas de deficiência de cálcio, que se manifestam como podridão apical dos frutos (VALE et al., 1995).

Nos substratos com resíduos de aves em sua composição (S4, S5 e S6), o teor de K foi bem superior ao teor de K do substrato comercial. Segundo Fernandes (2006), o teor de potássio na planta aumenta a taxa de absorção de $\mathrm{NO}_{3}{ }^{-}$e pode inibir a de cálcio e magnésio. Essa pode ser a causa de ocorrência de maior número de frutos com podridão apical nesses substratos. Além disso, no período de condução do experimento, foram registradas temperaturas extremamente baixas, próximas a $0^{\circ} \mathrm{C}$ (Figura 1), fazendo com que o fluxo hídrico na parte aérea fosse diminuído, diminuindo ainda mais o transporte de cálcio para os frutos.

A média do número total de frutos por planta foi de 20,61. Esse valor é maior que o obtido por Araújo et al. (2009) em que o número total de frutos por planta foi de 15,27 para a variedade All Big (pimentão do tipo "block" de coloração vermelha).

Cultura Agronômica, Ilha Solteira, v.26, n.4, p.502-513, 2017 
Tabela 2. Número de frutos normais (NFN), número de frutos com defeito leve (NFDL), número de frutos com defeito grave (NFDG), número total de frutos (NTF), massa de frutos normais (MFN), massa de frutos com defeito leve (MFDL), massa de frutos com defeito grave (MFDG), massa total de frutos (MTF), massa média dos frutos (MMF), diâmetro transversal do fruto (DTF), comprimento do fruto (COMP), espessura da polpa (EP), índice de formato do fruto (IFF) e produtividade (PROD) de pimentão em função do substrato e em função das cultivares.

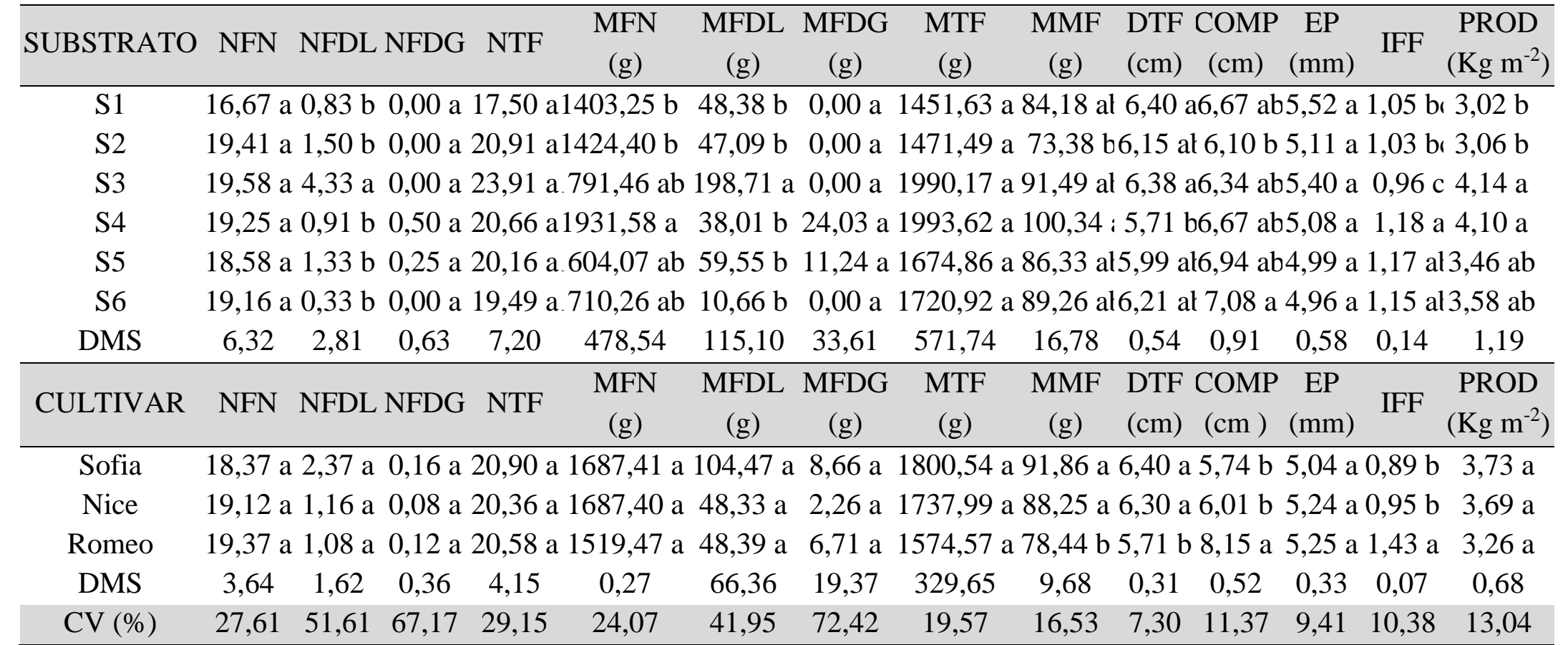

*Médias seguida de mesma letra na coluna não diferem entre si pelo teste de Tukey (p < 0,5); S1 - substrato comercial; S2 - composto orgânico; S3 - vermicomposto; S4 - composto orgânico e resíduo de aves na proporção 1:1 (V:V); S5 - vermicomposto e resíduo de aves na proporção 1:1 (V:V); S6 - composto orgânico, vermicomposto e resíduo de aves na proporção 1:1:1 (V:V:V); DMS - Diferença mínima significativa; CV - Coeficiente de variação.

Cultura Agronômica, Ilha Solteira, v.26, n.4, p.502-513, 2017 
As maiores massas de frutos normais foram obtidas no cultivo em vermicomposto (S3) e nos substratos contendo resíduo de aves em sua composição (S4, S5 e S6). A massa de frutos com defeito leve foi maior no cultivo em vermicomposto (S3), porém, mesmo assim o número de frutos normais foi semelhante aos substratos contendo resíduo de aves.

A massa média de frutos foi maior quando os frutos foram obtidos do cultivo em substrato contendo composto orgânico, vermicomposto e resíduo de aves na proporção 1:1:1 (S6), apesar de ter diferido apenas do cultivo em composto orgânico (S2). No substrato contendo composto orgânico, vermicomposto e resíduo de aves na proporção 1:1:1 o equilíbrio nutricional ser maior. Nesse substrato foi obtido teor de fósforo $109,92 \%$ superior ao substrato comercial, bem como teor de nitrogênio 64,20\% superior. O nitrogênio é um dos principais nutrientes necessários para as plantas, comprovado por Araújo et al. (2009) que verificaram que o peso médio dos frutos de pimentão aumentou à medida que as doses de nitrogênio aplicadas aumentaram. Nos substratos onde a concentração de resíduo de aves foi maior, apesar do aporte de nutrientes, estes apresentaram-se de forma desequilibrada, resultando em perdas na massa média de frutos.

Com relação às cultivares, a maior massa média dos frutos foi obtida para as cultivares Sofia e Nice (Tabela 2). Os frutos dessas cultivares são colhidos quando maduros. Sendo assim, eles permanecem mais tempo na planta, podendo acumular mais fotoassimilados e, consequentemente, obtendo maior massa.

A massa média dos frutos obtida neste experimento $(86,18 \mathrm{~g})$ foi inferior à obtida por Charlo et al. (2009) ao testar o cultivo de híbridos de pimentão em ambiente protegido, os quais obtiveram frutos com massa média de 203,35 g. Porém, isso pode ser inerente às características genéticas dos materiais testados ou às diferentes condições em que os experimentos foram conduzidos.

O menor diâmetro transversal foi observado nos frutos obtidos de plantas cultivadas no substrato S4 (composto orgânico e resíduos de aves (1:1)) e o maior nos substratos S1 (substrato comercial) e S3 (vermicomposto). No entanto estes não diferiram dos cultivados nos substratos S2 (composto orgânico), S5 (vermicomposto e resíduo de aves (1:1)) e S6 (composto orgânico, vermicomposto e resíduo de aves (1:1:1)) (Tabela 2).

Para o fator cultivar, o maior diâmetro transversal dos frutos foi obtido nas cultivares Sofia e Nice. O maior comprimento dos frutos foi observado na cultivar Romeo, o que é esperado, em função do formato retangular apresentado pelo fruto. Com relação aos substratos, nota-se maior comprimento dos frutos no substrato S6, apesar de ter diferido apenas do comprimento de frutos cultivados no substrato S2 (Tabela 2).

$\mathrm{O}$ índice de formato dos frutos foi maior nos frutos obtidos de plantas cultivadas em substrato contendo composto orgânico e resíduo de aves na proporção 1:1. Frutos mais alongados, tanto retangulares quanto cônicos, apresentam uma relação mais distante de "1". De acordo com Charlo et al. (2009), os consumidores têm preferência por frutos de formato 
quadrado, portanto, os frutos obtidos nos substratos vermicomposto (S3), composto orgânico (S4) e substrato comercial (S1) tendem a ter melhor aceitação no mercado.

As cultivares Nice e Sofia apresentaram valores mais próximos de "1" para a variável índice de formato do fruto. Isso se deve as características do material genético utilizado. As cultivares Sofia e Nice são pertencentes ao grupo "block", ou seja, são frutos com aspecto mais quadrado do que a cultivar Romeo, que pertence ao tipo retangular, possuindo, assim, frutos mais compridos e com maior índice de formato de fruto.

A média geral da espessura de polpa foi de 5,17 mm. Charlo et al. (2009) encontraram espessura da polpa de 6,01 mm para híbridos do tipo quadrado. Frizzone et al. (2001), ao trabalhar com pimentão do tipo amarelo, verificaram médias variando de 2,5 a 5,6 mm. É importante ressaltar que os frutos que possuem maior espessura são mais resistentes ao transporte, resultando também em maior durabilidade pós-colheita e maior rendimento em massa.

A maior produtividade foi verificada em plantas cultivadas em vermicomposto (S3) e composto orgânico com resíduo de aves na proporção 1:1 (S4), mesmo não diferindo dos substratos vermicomposto com resíduo de aves na proporção 1:1 (S5) e composto orgânico, vermicomposto e resíduo de aves na proporção 1:1:1 (S6). Isso pode ter ocorrido devido ao maior teor de nutrientes presentes nesses substratos. Bhat et al. (2013) concluíram que para o cultivo de tomate e pimentão, substratos formulados com vermicomposto em maior proporção foram melhores que outros em promover o crescimento da planta, produção e qualidade dos frutos. Segundo esses autores, esse tipo de substrato influencia positivamente a população microbiológica da rizosfera e contribui para o bom desenvolvimento inicial das mudas.

A produtividade média foi de $3,56 \mathrm{~kg} \mathrm{~m}^{-2}$, superando a produtividade obtida por Ribeiro et al. (2000), que obtiveram produtividade de $1,72 \mathrm{~kg} \mathrm{~m}^{-2}$ ao adubar a cultura com esterco de curral e $1,60 \mathrm{~kg} \mathrm{~m}^{-2}$ ao realizar a adubação com vermicomposto. Porém, Factor et al. (2008), obtiveram produtividade de $5,25 \mathrm{~kg} \mathrm{~m}^{-2}$ ao testar a produção de pimentão com adubação orgânica (efluente de biodigestor).

Segundo Factor et al. (2008), é difícil a comparação de produção entre as pesquisas realizadas com a cultura do pimentão em ambiente protegido, em virtude dos mais variados conceitos utilizados pelos autores. Neste sentido, sugere-se que nas pesquisas sejam obtidas as produtividades levando-se em consideração a classificação dos frutos, além do tempo entre a semeadura e a última colheita.

Durante o período de condução do experimento foram registradas temperaturas extremamente baixas (Figura 1). Essas baixas temperaturas registradas durante o ciclo de cultivo podem ter sido determinantes para as menores produtividades observadas. Segundo Costa e Henz (2007), a temperatura mínima ideal é de $18{ }^{\circ} \mathrm{C}$. Segundo esses autores, os efeitos das baixas temperaturas podem reduzir quantitativamente e qualitativamente a

Cultura Agronômica, Ilha Solteira, v.26, n.4, p.502-513, 2017 
produção do pimentão, sendo possível observar a queda de folhas, flores e frutos, além de estiolamento de folhas maduras, murcha de partes jovens e crescimento lento.

\section{CONCLUSÃO}

O resíduo de aves pode ser considerado uma alternativa em potencial para reduzir os custos de produção no cultivo em substratos e, principalmente, evitar o descarte desse material ainda rico em nutrientes no meio ambiente. As cultivares Sofia e Nice são as mais adequadas, por apresentarem maior massa média dos frutos e formato quadrado.

\section{REFERÊNCIAS BIBLIOGRÁFICAS}

ANDRIOLO, J. L.; DUARTE, T. S.; LUDKE L.; SKREBSKY, E. C. Caracterização e avaliação de substratos para o cultivo do tomateiro fora do solo. Horticultura Brasileira, Brasília, v. 17, n. 3, p.215-219, 1999.

ANDRIOLO, J. L.; WITTER, M; ROSS, T. D.; GODÓI, R. S. Crescimento e desenvolvimento do tomateiro cultivado em substrato com reutilização da solução nutritiva drenada. Horticultura Brasileira, Brasília, v. 21, n. 3, p.485-489, 2003.

ARAÚJO, J. S.; ANDRADE, A. P.; RAMALHO, C. I.; AZEVEDO, C. A. V. Características de frutos de pimentão cultivado em ambiente protegido sob doses de nitrogênio via fertirrigação. Revista Brasileira de Engenharia Agrícola e Ambiental, Campina Grande, v. 13, n. 2, p.152-157, 2009.

AYERS, R. S.; WESTCOT, D. W. A qualidade da água na agricultura. Campina Grande: UFPB, 1999. 218 p.

BHAT, N.; AlBAHO, M.; SUlEIMAN, M.; GEORGE, B. T. P.; ALI, S. I. Growing substrate composition influences growth, productivity and quality of organic vegetables. Asian Journal of Agricultural Sciences, Borhawor, v. 5, n. 4, p.62-66, 2013.

CEAGESP. Programa Brasileiro para Modernização da Horticultura. Classificação Pimentão. Online. Disponível em: http://www.hortibrasil.org.br/classificacao/pimentao/pimentao.html. Acesso em: 10 jan. 2016.

CHARLO, H. C. O.; CASTOLDI, R.; FERNANDES, C.; VARGAS, P. F.; BRAZ, L. T. Cultivo de híbridos de pimentão amarelo em fibra da casca de coco. Horticultura Brasileira, Brasília, v. 27, n. 2, p.155-159, 2009.

COSTA, C. S. R.; HenZ, G. P. Pimenta (Capsicum spp.) - Sistema de Produção. Embrapa Hortaliças, $2007 . \quad$ Disponível em: http://sistemasdeproducao.cnptia.embrapa.br/FontesHTML/Pimenta/Pimenta_capsicum_sp/. Acesso em 12 jan. 2016.

Cultura Agronômica, Ilha Solteira, v.26, n.4, p.502-513, 2017 
DAREZZO, R. J.; AGUIAR, R. L.; AGUILERA, G. A. H.; ROZANE, D. E.; SILVA, D. J. $H$. Cultivo em ambiente protegido: histórico, tecnologias e perspectivas. Viçosa: UFV, 2004. $331 \mathrm{p}$.

FACTOR, T. L.; ARAÚJO, J. A. C.; VILELLA JÚNIOR, L. Produção de pimentão em substratos e fertirrigação com efluente de biodigestor. Revista Brasileira de Engenharia Agrícola e Ambiental, Campina Grande, v. 12, n. 2, p.143-149, 2008.

FERMINO, M. H. Métodos de análise para caracterização física de substratos para plantas. 2003. 104 p. Tese (Doutorado em fitotecnia) - Universidade Federal do Rio Grande do Sul, Porto Alegre, 2003.

FERNANDES, M. S. Nutrição mineral de plantas. Viçosa: Sociedade Brasileira de Ciência do Solo, 2006. 432 p.

FERREIRA, D. F. Sisvar: a computer statistical analysis system. Ciência e Agrotecnologia, Lavras, v. 35, n. 6, p.1039-1042, 2011.

FRIZZONE, J. A.; GONÇALVES, A. C. A.; REZENDE, R. Produtividade do pimentão amarelo, Capsicum annum L., cultivado em ambiente protegido em função do potencial mátrico de água no solo. Acta Scientiarum, Maringá, v. 23, n. 5, p.1111-1116, 2001.

HACHMANN, T. L.; LAURETH, J. C. U.; PARIZOTTO, A. A.; GONÇALVES JUNIOR, A. F. Resíduos de aves e suínos - potencialidades. Revista Verde de Agroecologia e Desenvolvimento Sustentável, Mossoró, v. 8, n. 5, p.59-65, 2013.

JADOSKI, C. J.; KIAR, A. E.; MAGGI, M. F.; RAMIRO, J.; SANTOS, A. R. A.; FURLAN, S. R. Distribuição da evaporação no interior de um ambiente protegido. Irriga, Botucatu, v. 11, n. 2, p.246-256, 2006.

MACHADO, C. A.; RODRIGUES, C. D. S.; WEIRICH, M.; CHAGAS, P. R. R. Avaliação de híbridos e cultivares de tomateiro cultivado no sistema de agricultura natural protegido. In: CONGRESSO BRASILEIRO DE OLERICULTURA, 42, 2002, Uberlândia. Anais... Brasília: ABH, 2002. p. 394-396. CD-ROM

MElO, G. W. B.; BORTOlOZZO, A. R.; VARGAS, L. Produção de morangos no sistema semi-hidropônico. Embrapa Uva e Vinho, 2006. Disponível em: http://sistemasdeproducao.cnptia.embrapa.br/FontesHTML/Morango/MorangoSemiHidropo nico/substratos.htm. Acesso em: 03 fev. 2016.

RIBEIRO, L. G.; LOPES, J. C.; MARTINS FILHO, S.; RAMALHO, S. S. Adubação orgânica na produção de pimentão. Horticultura Brasileira, Brasília, v. 18, n. 2, p.134$137,2000$.

SANJUÁN, M. C. S.; GAVILÁN, U. M. El cultivo del pimiento. In: GAVILAN, M.U. Tratado de cultivo sin suelo. Madri: Ediciones Mundi-Prensa, 2004. 914 p.

SILVA, F. C. Manual de análises químicas de solos, plantas e fertilizantes. Brasília: Embrapa Informação Tecnológica, 2009. 627 p.

Cultura Agronômica, Ilha Solteira, v.26, n.4, p.502-513, 2017 
VALE, F. R.; GUILHERME, L. R. G.; GUEDES, G. A. A. Fertilidade do solo, dinâmica e disponibilidade nutrientes de plantas. Lavras: UFLA/FAEPE, 1995. $171 \mathrm{p}$.

VIDA, J. B.; ZAMBOLIM, L.; TESSMANN, D. J.; BRANDÃO FILHO, J. U. T.; VERZIGNASSI, J. R.; CAIXETA, M. P. Manejo de doenças de plantas em cultivo protegido. Fitopatologia Brasileira, Brasília, v. 19, n. 4, p.355-372, 2004. 